\title{
Best practice guidelines for molecular genetic diagnosis of cystic fibrosis and CFTR-related disorders - updated European recommendations
}

\author{
Els Dequeker ${ }^{1}$, Manfred Stuhrmann $^{2}$, Michael A Morris $^{3}$, Teresa Casals ${ }^{4}$, Carlo Castellani $^{5}$, \\ Mireille Claustres ${ }^{6}$, Harry Cuppens ${ }^{1}$, Marie des Georges ${ }^{6}$, Claude Ferec ${ }^{7}$, Milan Macek ${ }^{8}$, \\ Pier-Franco Pignatti ${ }^{9}$, Hans Scheffer ${ }^{10}$, Marianne Schwartz ${ }^{11}$, Michal Witt ${ }^{12}$, \\ Martin Schwarz ${ }^{13}$ and Emmanuelle Girodon*,14
}

${ }^{1}$ Center for Human Genetics, Campus Gasthuisberg, KULeuven, Belgium; ${ }^{2}$ Institut für Humangenetik, Medizinische Hochschule, Hannover, Germany; ${ }^{3}$ Laboratoire de Diagnostic moléculaire, Service de Médecine Génétique, University Hospital, Geneva, Switzerland; ${ }^{4}$ Centre de Genetica Medica i Molecular, IDIBELL, Barcelona, Spain; ${ }^{5}$ Cystic Fibrosis Centre, Ospedale Civile Maggiore, Verona, Italy; ${ }^{6}$ Service de Génétique Moléculaire, CHU and INSERM U827, Montpellier, France; ${ }^{7}$ Laboratoire de Génétique Moléculaire, Brest, France; ${ }^{8}$ Department of Biology and Medical Genetics, 2nd School of Medicine and University Hospital Motol, Charles University Prague, Czech Republic; ${ }^{9}$ Section of Biology and Genetics, University of Verona, Italy; ${ }^{10}$ Department of Human Genetics, Radboud University Nijmegen Medical Centre, Nijmegen, The Nederlands; ${ }^{11}$ Molekyloergenetisk laboratorium, Klinisk genetisk afdeling, Copenhagen, Denmark; ${ }^{12}$ Department of Molecular and Clinical Genetics, Institute of Human Genetics, Poznan, Poland;

${ }^{13}$ Department of Medical Genetics, St Mary's Hospital, Manchester, UK; ${ }^{14}$ Service de Biochimie et Génétique, Groupe hospitalier Henri Mondor-Albert Chenevier, APHP, Créteil, France

The increasing number of laboratories offering molecular genetic analysis of the CFTR gene and the growing use of commercial kits strengthen the need for an update of previous best practice guidelines (published in 2000). The importance of organizing regional or national laboratory networks, to provide both primary and comprehensive CFTR mutation screening, is stressed. Current guidelines focus on strategies for dealing with increasingly complex situations of CFTR testing. Diagnostic flow charts now include testing in CFTR-related disorders and in fetal bowel anomalies. Emphasis is also placed on the need to consider ethnic or geographic origins of patients and individuals, on basic principles of risk calculation and on the importance of providing accurate laboratory reports. Finally, classification of CFTR mutations is reviewed, with regard to their relevance to pathogenicity and to genetic counselling.

European Journal of Human Genetics (2009) 17, 51-65; doi:10.1038/ejhg.2008.136; published online 6 August 2008

Keywords: guidelines; recommendations; genetic testing; cystic fibrosis; CFTR; CFTR-related disorders

\section{Introduction}

Cystic fibrosis transmembrane conductance regulator (CFTR) gene studies represent one of the most frequent

*Correspondence: Dr E Girodon, Service de Biochimie et Génétique, Groupe hospitalier Henri Mondor-Albert Chenevier, APHP, 51, av du Maréchal de Lattre de Tassigny, Créteil 94010, France.

Tel: 331498128 57; Fax: 331498128 42;

E-mail: emmanuelle.girodon@inserm.fr

Received 16 January 2008; revised 23 June 2008; accepted 26 June 2008; published online 6 August 2008 genetic analyses routinely performed worldwide. Such tests are carried out in various situations, including molecular diagnosis of cystic fibrosis (CF), prenatal diagnosis, and carrier testing. CF is primarily a clinical diagnosis based on consensus clinical and laboratory criteria. ${ }^{1}$ Detailed phenotypic characteristics can be found elsewhere. ${ }^{1-5}$ Laboratory criteria include a positive sweat test (chloride value above $60 \mathrm{mEq} / \mathrm{l}$ ), and/or presence of two CF-causing mutations (in trans), and/or abnormal values of electrophysiological measurements, that is, nasal potential difference and rectal 
chloride transport. More than 1500 sequence variations have been reported in the CFTR gene, often with geographic or ethnic variations in frequency ${ }^{6-8}$ and which are found in both CF and related phenotypes, named CFTR-related disorders (CFTR-RD). These are clinical entities associated with CFTR dysfunction but where the diagnosis of CF cannot be unambiguously established; ${ }^{1}$ for example, congenital bilateral absence of vas deferens $(\mathrm{CBAVD})^{9-13}$ disseminated bronchiectasis, ${ }^{14,15}$ chronic pancreatitis, ${ }^{16,17}$ or chronic rhinosinusitis. ${ }^{18,19}$

CFTR gene analyses are performed in specialist clinical molecular genetics laboratories closely associated with clinical genetic services or research facilities, and also in private laboratories; lists of European laboratories offering CFTR genetic testing are available at www.orpha.net or at www.eurogentest.org/web/qa/basic.xhtml. A good knowledge of CFTR diseases and their molecular pathology is required when choosing tools and strategies and when interpreting results. Genetic testing should only be performed in the context of appropriate genetic counselling and laboratories should work in close association with clinical geneticists and reference laboratories to ensure that pertinent tests are performed and proper information is provided to the patients. The need for organization of regional or national networks of laboratories is thus emphasized.

Previous recommendations for quality improvement in CF genetic analysis were published in 2000 under the aegis of the European Concerted Action on Cystic Fibrosis. ${ }^{20}$ These recommendations have been widely implemented in the framework of national or regional networks of diagnostics laboratories. However, an update has become necessary since many more laboratories are now offering CFTR genetic testing; the number of and indications for referrals have increased, in particular in the area of male infertility; knowledge of CFTR molecular pathology has evolved; and laboratory practice has changed, notably in the methods used. Moreover, 10 years experience of European external quality assessment (EQA) shows that, although there has been steady improvement in the quality of CFTR testing, many issues still need to be addressed. In addition, a number of initiatives have been taken, aiming at international consensus and the development of best practice guidelines for molecular genetic services either in general terms, for example, by the $\mathrm{OECD}^{21}$ or the Network of Excellence 'EuroGentest' (www.eurogentest.org), or specifically for CF such as the Concerted Action 'EuroCareCF' (www.eurocarecf.eu) and the Neonatal Screening Working Group of the European Cystic Fibrosis Society (www.ecfs.eu). ${ }^{22}$ Invaluable efforts have also been made by American colleagues to edit standards and guidelines for CFTR testing, in particular through the American College of Medical Genetics (www.acmg.net) and the American College of Obstetricians and Gynecologists (www.acog.org), and Cystic Fibrosis
Foundation tasks (www.cff.org) ${ }^{23-25}$ Harmonization and consensus among these initiatives are critical.

The present guidelines are the result of a conference held in Manchester, 25-26 October 2006, with the partnership of EuroGentest and the CF Network (www.cfnetwork.be). This meeting involved 15 experts in the field of CF and molecular diagnostics, from 11 European countries. The main purpose was to provide molecular geneticists involved in CFTR genetic testing with recommendations for testing and reporting of molecular genetic analysis. Reference laboratories are encouraged to discuss, validate, and facilitate implementation of these recommendations within their national or regional networks.

\section{Methods for CFTR gene analysis Methods for CFTR mutation detection}

CFTR molecular testing mainly relies on direct gene analysis procedures, that is, the detection of diseasecausing mutations, which are based on our knowledge of CFTR molecular pathology and on the availability of molecular tools for detecting mutations. A wide range of techniques is used to identify CFTR gene sequence variations and there is no gold standard for routine testing. All available methods require skill and experience to perform and interpret. There is no standard or preferred method(s), but laboratories should be aware of the limitations of their chosen method and should know which mutations are not identified, whether the techniques are commercially available or developed within the laboratory. This means that individual laboratories should choose a method, which is suited to their experience, workload, and scope of testing.

Methods used in CFTR testing can be divided into two groups: those targeted at known mutations (ie, testing DNA samples for the presence or absence of specific mutation(s)) and scanning methods (ie, screening samples for any deviation from the standard sequence). These now include searching for large unknown CFTR rearrangements, including large deletions, insertions, and duplications, by semiquantitative PCR experiments, that is, multiplex ligation-dependant probe amplification (MLPA) or quantitative fluorescent multiplex PCR. ${ }^{26-28}$ Such rearrangements, which can escape detection using conventional amplification assays, have been shown to occur in up to $2 \%$ of alleles in CF patients ${ }^{26-30}$ and $1 \%$ in CBAVD patients. $^{13}$

The features of the methods currently applied are summarized in Table 1 . The list is not exhaustive and will need regular updates with the advent of new validated technologies, such as high-resolution melting curve analysis (HRMCA). ${ }^{31}$ Furthermore, commercial assays also evolve to meet the users' requests. The CF Network provides an annual overview of mutations tested by 
Table 1 Methods for CFTR gene mutation detection most frequently used in Europe

\begin{tabular}{|c|c|c|c|}
\hline $\begin{array}{l}\text { Methods for the detection of } \\
\text { known mutations }\end{array}$ & Mutations detected & Advantages & Limits and pitfalls \\
\hline $\begin{array}{l}\text { Heteroduplex analysis (strictly } \\
\text { speaking a scanning method) }\end{array}$ & $\begin{array}{l}\text { Mainly F508del and 1507del } \\
\text { Other microinsertions/deletions } \\
\text { (2 bp minimum): 394delTT } \\
\text { (Northern Europe), 1677delTA } \\
\text { (Black Sea countries), } \\
\text { 1609delCA (Spain) }\end{array}$ & Simple and rapid & $\begin{array}{l}\text { Migration pattern not specific } \\
\text { for a given mutation }\end{array}$ \\
\hline $\begin{array}{l}\text { Restriction enzyme analysis } \\
\text { (restriction sites can be natural } \\
\text { or created by the use of modified } \\
\text { primers) }\end{array}$ & $\begin{array}{l}\text { Mainly specific individual } \\
\text { mutations } \\
\text { Possibly a small number of } \\
\text { mutations can be combined } \\
\text { in one assay }\end{array}$ & $\begin{array}{l}\text { Simple and rapid } \\
\text { Useful for cascade carrier } \\
\text { testing in case of rare } \\
\text { mutations }\end{array}$ & \multirow[t]{3}{*}{$\begin{array}{l}\text { Not specific, especially if site } \\
\text { abolition (eg, G551D and } \\
\text { R553X abolish the same Hinc II } \\
\text { site, and W1282X and R1283M } \\
\text { the same Mnl I site) }\end{array}$} \\
\hline Reverse dot blot hybridization & $\begin{array}{l}\text { Up to } 20 \text { mutations per } \\
\text { multiplex }\end{array}$ & Appropriate for large series & \\
\hline Innogenetics (Inno LiPA) ${ }^{\mathrm{a}}$ & 36 mutations & Good specificity & \\
\hline $\begin{array}{l}\text { ARMS (amplification refractory } \\
\text { mutation system) }\end{array}$ & Up to 20 mutations & Appropriate for large series & \multirow[t]{4}{*}{$\begin{array}{l}\text { Design of primers is difficult } \\
\text { Results are based on the } \\
\text { absence of PCR product }\end{array}$} \\
\hline Tepnel (Elucigene) ${ }^{\mathrm{a}}$ & $28-30$ mutations & Good specificity & \\
\hline $\begin{array}{l}\text { OLA (oligonucleotide ligation } \\
\text { assay) }\end{array}$ & & Appropriate for large series & \\
\hline $\begin{array}{l}\text { Abbott Molecular (Cystic Fibrosis } \\
\text { Genotyping Assay) }\end{array}$ & 32 mutations & Good specificity & \\
\hline
\end{tabular}

Methods for the detection of unknown mutations

DGGE (denaturing gradient gel

electrophoresis)

DHPLC (denaturing high performance liquid chromatography)

SSCP (single strand conformation polymorphism)

Sequencing (as a first-line method or confirmation after a scanning technique)

Quantitative fluorescent multiplex PCR

MLPA (multiple ligation-dependent probe amplification)
High sensitivity (>95\%)

DGGE, DHPLC, SSCP and

Sequencing:

Aiming to detect all mutations of small bp in the coding regions and intronic boundaries

High sensitivity (>95\%)

Aiming to detect deletions, insertions, and duplications All coding regions

Close to $100 \%$ sensitivity

Simple and rapid
Difficult to set up; difficult automation

Can miss isostable mutations in the homozygous state

Generally miss homozygous mutations

Need sequencing of

polymorphism-rich regions

Simple and rapid to set up

Sensitivity $80-85 \%$

Sensitive to extraction methods Duplications may be difficult to evidence

${ }^{a}$ Commercially available methods are indicated in italics

commercial assays used by the participants of its EQA scheme (www.cfnetwork.be). Even though commercial kits may be CE-marked in vitro diagnostic devices (IVDD), assay performance should always be verified by laboratories before diagnostic use. The combined use of all these techniques cannot guarantee detection of the two disease-causing mutations (in trans - ie, on both parental alleles) in all patients; $1-5 \%$ of alleles remain undetermined in CF patients with the classical form and even more in patients with atypical presentations. Moreover, the percentage of undetected mutations increases from northern to southern European populations. CFTR mutations may 
Table 2 Indications for CFTR microsatellite markers studies

- Segregation analysis in a family, when one or no CF-causing mutations have been found (CF diagnosis must be definite)

- Indirect evidence of a large rearrangement (abnormal segregation of intragenic markers)

- Elucidation of a suspected uniparental disomy

- Exclusion of CF by linkage studies in a family with at least two siblings (misinterpretation is possible in case of phenotypic heterogeneity in affected siblings)

- Detection of maternal contamination in prenatal diagnosis

- Identification of haplotypes associated with CF-causing mutations in highly heterogeneous populations

be missed by scanning techniques, especially when homozygous, and even direct sequencing cannot identify $100 \%$ of mutations.

Undetected CFTR mutations may lie within the introns or regulatory regions, which are not routinely analysed. It should also be noted that locus heterogeneity has been documented in patients with the classical form of $\mathrm{CF}$ including a positive sweat test, ${ }^{32,33}$ but probably concerns less than $1 \%$ of cases. Mutations in the SCNN1 genes, encoding sodium channel (ENaC) subunits, have recently been found in non-classic CF cases where no CFTR mutations could be identified by extensive mutation scanning. ${ }^{34}$ However, the diagnostic utility of $\mathrm{ENaC}$ testing in routine practice has not been determined.

\section{Analysis of CFTR microsatellite markers}

Besides direct gene analysis procedures, analysis of polymorphic CFTR markers ${ }^{35-39}$ may be helpful in particular situations (Table 2). Although recombination within the CFTR gene is very rare, the use of multiple microsatellite markers is recommended for family studies.

\section{Guidelines for CFTR testing}

\section{Organization of $C F T R$ testing provision}

The extensive heterogeneity in the distribution of CFTR gene mutations in European populations ${ }^{6-8}$ makes the goal of a mutation detection rate of over $95 \%$ very hard to achieve, except with a combination of scanning methods. Efforts should be made to provide testing of reasonably high sensitivity and to detect all CF-causing mutations with a frequency above $1 \%$ in the local population. However, because a number of situations require additional testing beyond a local panel, and because many laboratories now exclusively use a commercial kit, collaborative networks of laboratories are critical. Laboratories should be aware of the fact that companies usually optimize their panels for American and/or Western European populations. As a consequence, the sensitivity of the test varies between populations and may be low in certain regions,
Table 3 Recommended criteria for testing laboratories

'Level 1 '

- Performs CFTR testing in the context of a genetic diagnostic laboratory

- Works within a comprehensive quality management system (accreditation or equivalent)

- Uses validated methods

- Participates annually in a national or international EQA scheme for CF

- Makes sure tests are referred through physicians or genetic professionals and informed consent is obtained from the individuals to be tested

- Assures pretesting and post-testing referrals to collaborating genetic counselling services

- Ideally screens for all CF-causing mutations with a frequency above $1 \%$ within its population

- Issues reports including appropriate and understandable interpretation of the genotypes

- Has a defined turn around time (TAT)

- Has a formal arrangement with a level 2 laboratory for complex cases

'Level 2'

- Fulfils all but last requirement of level 1 laboratory

- Acts as a reference and consulting centre for resolving complex cases and is able to detect all types of mutations using available techniques

- Acts in a consultancy capacity for test validation, clinical genetics, education, and training of laboratory staff

- Is involved in network management (ie, organizing network education meetings on regular basis)

- Evaluates new techniques or technologies related to CFTR testing

- Is closely related to or involved in CF research (translational CF research)

- Encourages and coordinates participation of collaborating laboratories in EQA schemes

notably Central, Southern and Eastern Europe. Practical organization of laboratories at two levels of expertize should ideally be agreed within a particular region or country. Table 3 summarizes criteria for laboratories of 'level 1' (screening) and 'level 2' (reference) laboratories. Laboratories should be aware of the actual or estimated mutation detection rate in any given situation and determine when rare or specific mutations should be sought, possibly in a 'level 2' laboratory.

\section{Pretest requirements}

The quality of the final result depends not only on the laboratory procedures themselves, but also on the referral information, which must be sufficient to allow correct selection of the precise test. Questionnaires to this end can be made available by laboratories.

Informed consent should be obtained in compliance with applicable legal, ethical, and professional standards. Pretest and post-test counselling, proportionate to the significance of test results, should be available to individuals and their relatives. ${ }^{21}$ 


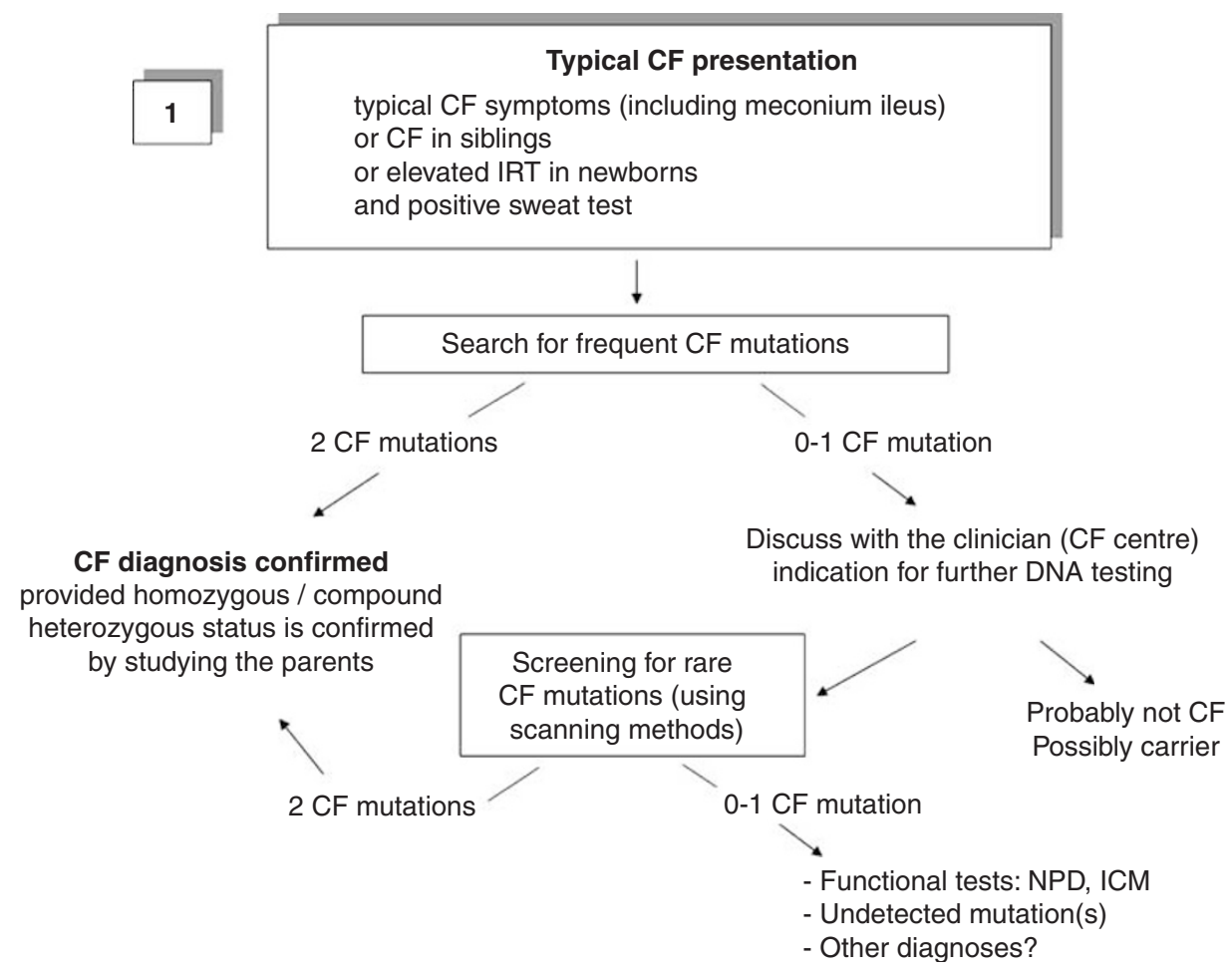

Figure 1 Diagnostic testing in typical CF presentation. The diagnostic algorithm applies irrespective of the age of the CF patient, from newborn screening to late diagnosis in adults. While the diagnosis of CF can be based on the presence of one or more characteristic phenotypic features, ${ }^{1}$ a classical or typical clinical CF presentation mainly associates respiratory symptoms with pulmonary obstruction and infections, exocrine pancreatic dysfunction, and infertility in adult males, along with sweat chloride concentrations above $60 \mathrm{mEq} / \mathrm{l}$ that provide an evidence of a CFTR defect. IRT, immunoreactive trypsinaemia; NPD, nasal potential difference; ICM, intestinal chloride measurement.

In the case of family studies, no information regarding carrier status should be communicated to the third parties without the consent of the individual tested.

\section{Indications for CFTR testing}

Appropriate strategies and decision procedures for diagnostic testing in different situations and for carrier testing are presented as flow charts or discussed in the following sections.

\section{Indications for CFTR testing}

- Diagnostic testing in typical CF presentation (Figure 1)

- Diagnostic testing in atypical clinical presentation and/ or borderline sweat test (Figure 2)

- Diagnostic testing in male infertility with CBAVD (Figure 3)

- Diagnostic testing in other CFTR-RD in adults

- Diagnostic testing in fetuses with bowel hyperechogenicity and/or loop dilatation (Figure 4)

- Prenatal diagnosis

- CF carrier testing in individuals with a positive family history (Figure 5)

- CF carrier screening in individuals without a family history $^{\mathrm{a}}$

- CF carrier testing in infertile couples ${ }^{\mathrm{a}}$
${ }^{\mathrm{a}} \mathrm{CF}$ carrier screening/testing in these situations may not be recommended, depending on national policies and regulations, but has been addressed.

Specific situations can be handled individually, beyond the suggested flow charts. In particularly difficult situations, it is essential that the diagnostic strategies are shared with the referring clinician and/or a 'level 2' laboratory.

As in the previous guidelines, diagnostic testing should be considered within the context of a diagnostic algorithm, as published elsewhere. ${ }^{41}$

\section{General guidance for reading flow charts}

In all instances in the flow charts, the search for frequent CF-causing mutations refers to the screening of a common panel as the first-step method. The respective panel may vary between laboratories because of the requirement of the local population, although, in most cases, the 'basic' panel may be determined by one of the available commercial assays.

As in all other autosomal recessive diseases, identification of mutation(s) on both parental alleles is required to confirm the diagnosis. Homozygous and compound heterozygous status should thus be confirmed by studying the parents. Moreover, the assignment of correct parental 


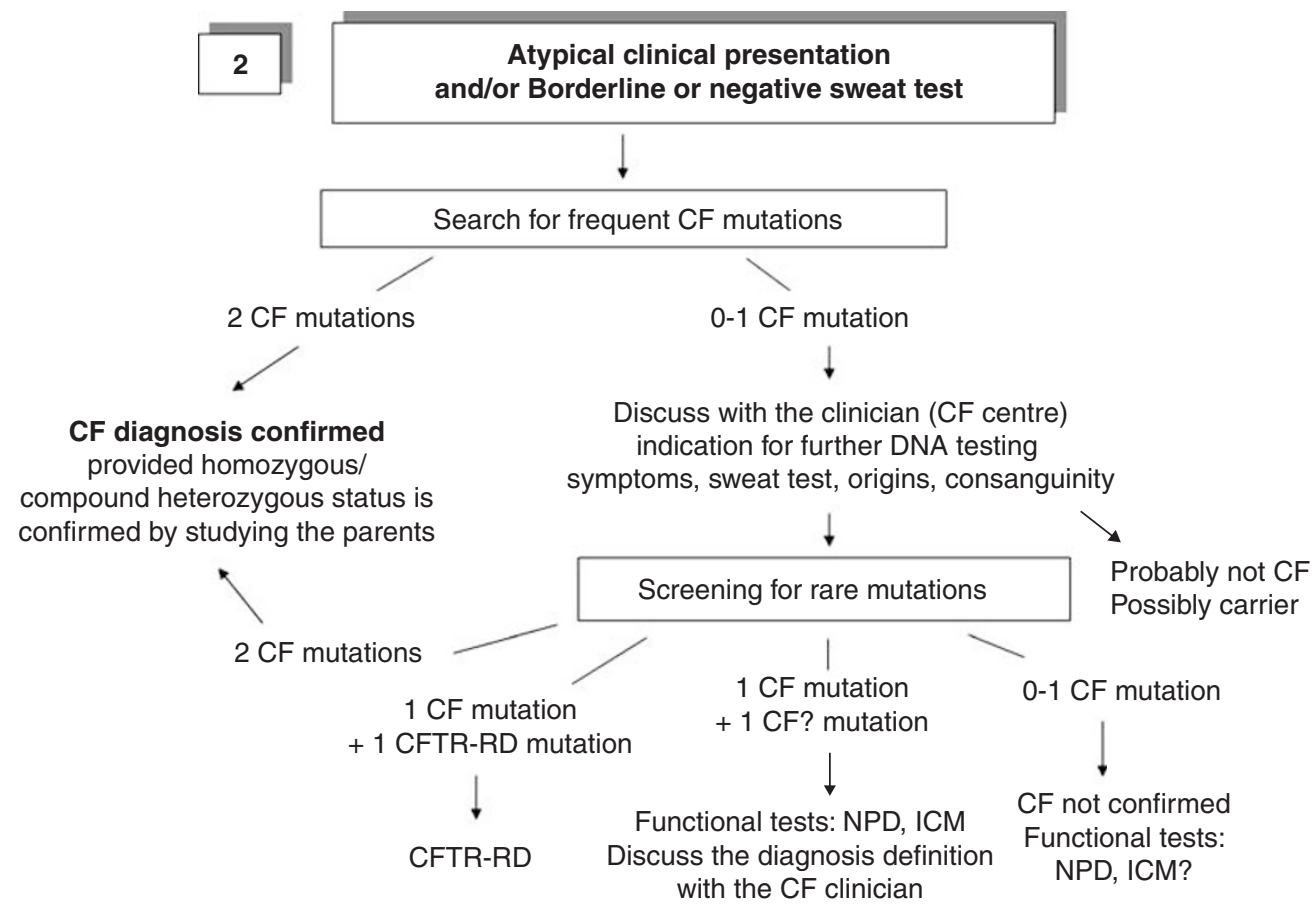

Figure 2 Diagnostic testing in atypical clinical presentation and/or borderline or negative sweat test. Genetic testing is requested to confirm the diagnosis. Patients most often have residual pancreatic function (pancreatic sufficiency) but may present with acute or chronic pancreatitis. Highly variable respiratory symptoms include asthma, nasal polyposis, chronic rhinosinusitis, or disseminated bronchiectasis. CFTR-RD, CFTR-related disorder(s); CF?, mutation of uncertain clinical relevance; NPD, nasal potential difference; ICM, intestinal chloride measurement.

alleles is required to prepare for possible prenatal diagnosis (PND) and for carrier testing in relatives.

De novo mutations have been described but are exceptionally rare. ${ }^{42,43}$ If the mutations are not found in the parents, laboratories should be aware of the possibility of non-paternity and sample mix-up. Uniparental disomy of chromosome 7 is also extremely rare and usually associated with atypical and/or syndromic presentation, including growth retardation or overgrowth. ${ }^{44-47}$

\section{Particular comments and recommendations for specific indications}

Male infertility with CBAVD In male infertility due to obstructive azoospermia, documented cases with CBAVD with strict diagnosis criteria (List below) have been shown to be commonly linked to CFTR mutations (Figure 3). CBAVD is the best known CFTR-RD. Extensive studies have shown that approximately $80 \%$ of patients with isolated CBAVD carry two CFTR mutations, usually in compound heterozygosity. ${ }^{9-13}$

\section{Diagnostic criteria for CFTR-related CBAVD}

- Azoospermia

- Low seminal fluid volume $(<2.0 \mathrm{ml})$

- Typical biochemical features: $\mathrm{pH}<7.2$, absent or decreased fructose and $\alpha 1-4$ glucosidase (markers of properly functioning seminal vesicles and epididymis, respectively)

- Absence of palpable vas deferens

- On transrectal ultrasound: absence of the intra-abdominal tract of the vas deferens, globus major, and different degrees of hypoplasia of the seminal vesicles. These anomalies may also be confirmed at surgical sperm retrieval.

- Normal plasma follicle-stimulating hormone (FSH), luteinizing hormone (LH), and testosterone levels

Whether patients with unilateral absence of vas deferens (CUAVD) or other renal-ureteral anomalies have an increased risk of carrying CFTR mutations remains controversial. ${ }^{11,48,49}$ Additional data should be provided to determine the utility of CFTR testing in these situations.

Other CFTR-RD in adults Chronic pancreatitis, disseminated bronchiectasis, or atypical chronic rhinosinusitis have been associated with an increased frequency of CFTR mutations. ${ }^{4,14-19,50}$ A thorough clinical examination at a specialized CF centre should be recommended, as these symptoms may suggest undiagnosed CF.

While comprehensive CFTR gene studies may not be widely advised in such situations, one could refer to flow 


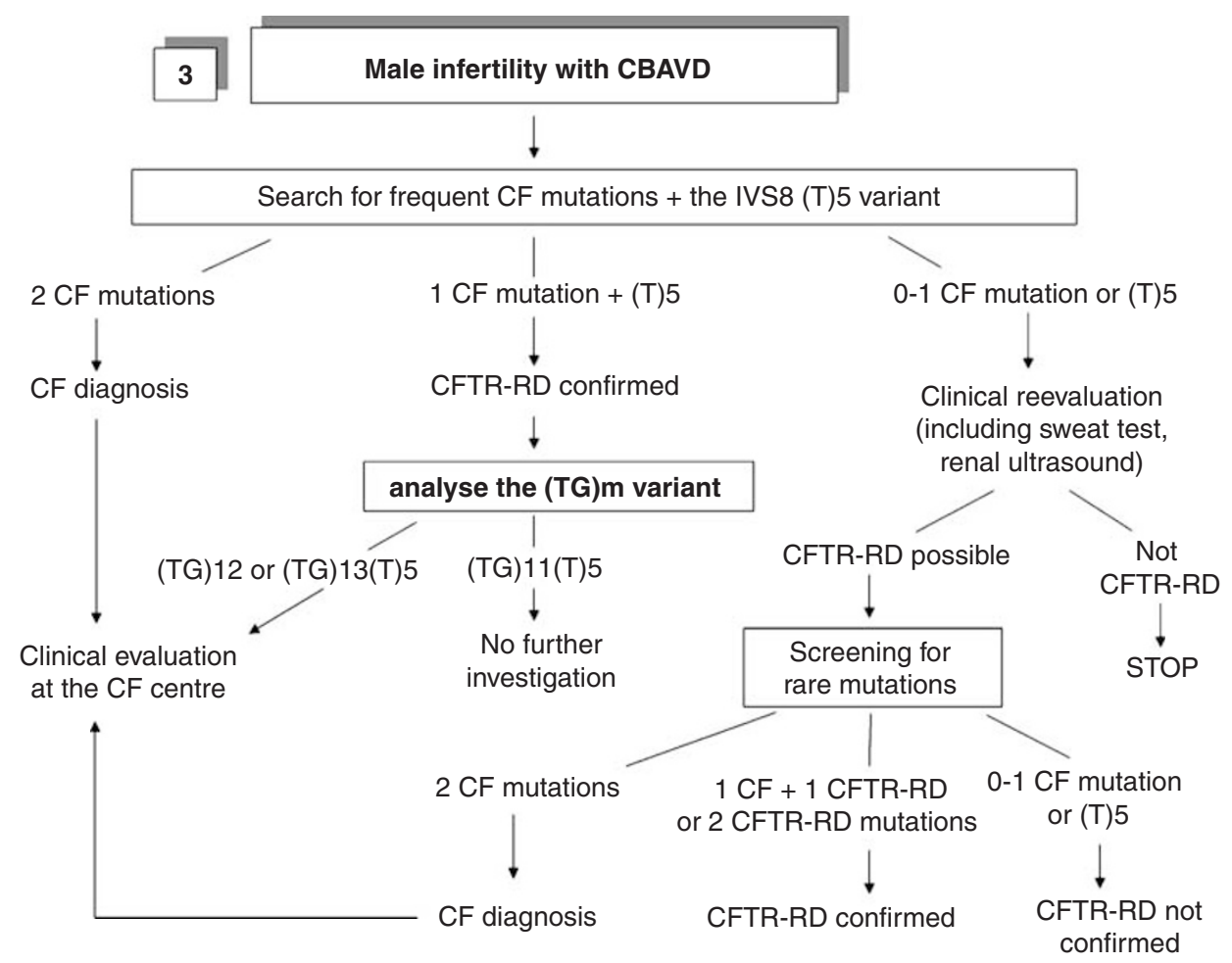

Figure 3 Diagnostic testing in male infertility with CBAVD. See text for diagnosis criteria for CFTR-related CBAVD. CFTR-RD, CFTR-related disorder(s).

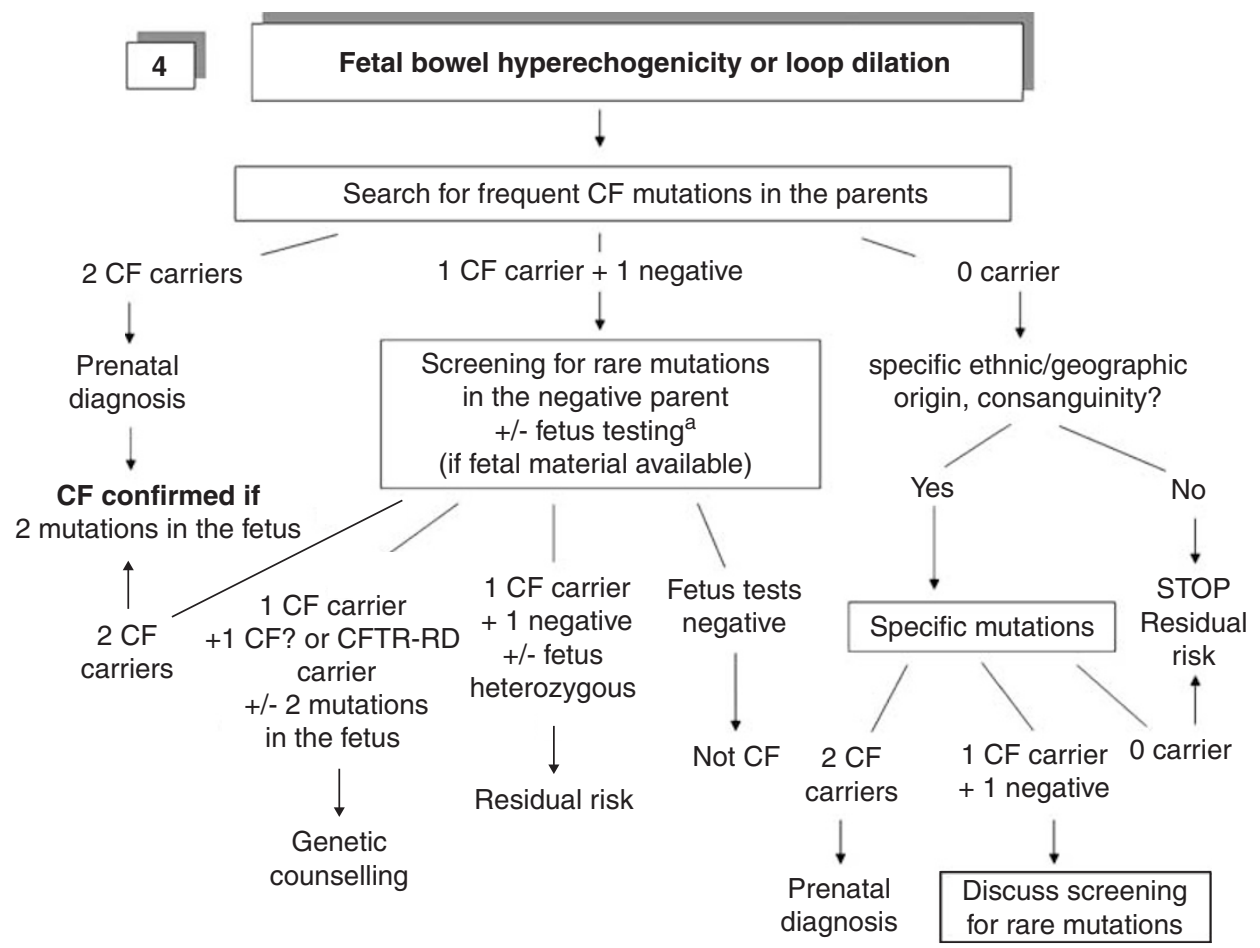

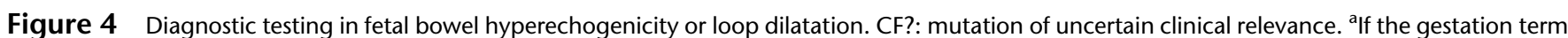
is below 18 weeks and amniocentesis is performed, evaluation of fetal intestinal enzyme activities in the amniotic fluid may be considered, a dramatic decrease of all activities being suggestive of intestinal obstruction. 


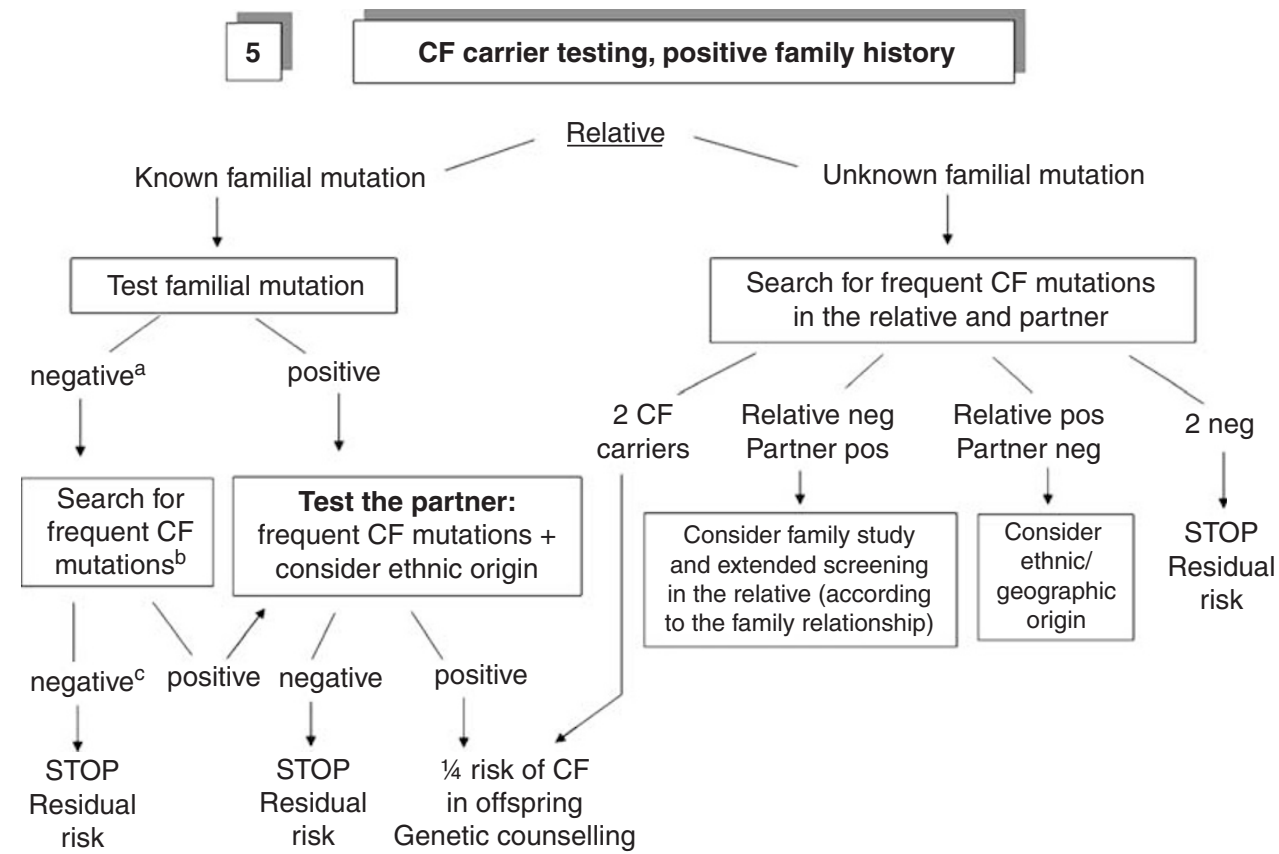

Figure 5 Cascade CF carrier testing. The purpose of carrier testing is to provide individuals with reproductive options and allow informed choices. Carrier testing in children should be deferred until the child can understand the issue and request the test in person. ${ }^{40}$ a Reporting a negative result for familial mutation testing should be carried out cautiously if the mutation has been identified in another laboratory, unless a copy of the original report is available to the laboratory in charge of the test. ${ }^{b}$ Test for the familial mutation may be performed in the same step as for the frequent mutations. ${ }^{\mathrm{C}}$ In case the familial mutation is known and both couple members are tested in the same time, if the relative unexpectedly tests 'negative' and the partner tests 'positive', especially for the familial CF mutation, it is recommended to confirm the results, possibly with new samples and/or using microsatellite assays.

chart 2. Attention should be paid to: early onset of the disease and the presence of other symptoms or laboratory signs suggestive of CF (in particular CBAVD in males, see above); request for genetic counselling for the patients or their relatives.

Suspicion of CF in fetuses with bowel hyperechogenicity and/or loop dilatation Fetal bowel anomalies are most often observed during the ultrasound examinations in the second trimester of pregnancy (Figure 4). They can be due to CF or other disease conditions or may be not associated with disease. Diagnostic investigations should therefore include searching for frequent CFTR mutations, fetal karyotyping, and screening for viral infections (in particular cytomegalovirus). ${ }^{51}$ However, depending on national regulation and maximum term for termination of pregnancy, this situation may not lead to diagnostic investigations.

While the overall risk of CF varies between studies, ${ }^{52-56}$ a large French collaborative study of 641 pregnancies presenting varied fetal bowel anomalies, determined the risk of CF as $3 \% .{ }^{54}$ Significant anomalies were grade III hyperechogenicity (ie, where the ultrasound echogenicity of the fetal abdomen was equal to the surrounding bone tissue) and loop dilatation.
Prenatal diagnosis Laboratories that perform PND should fulfil all requirements of 'level 1' laboratories (Table 3). PND should be performed on request, following genetic counselling, and can be offered to: (1) parents of a patient with a clear diagnosis of $\mathrm{CF}$, where both parental mutations have been identified. If one or both $\mathrm{CF}$ mutations have not been identified in the index case, assessment of the parents' CF carrier status or construction of parental CFTR haplotypes should be performed before PND. (2) Carrier couples identified through carrier testing. (3) Carrier couples identified through investigations for fetal bowel anomalies.

Recommendations for PND practice:

- All molecular analysis required for the PND should be performed within the same laboratory and by experienced staff.

- Search for maternal cell contamination of the fetal sample and for sample mix-up should be carried out by studying a panel of microsatellite markers.

- Parents and index case should be reanalysed and run in parallel with the fetal sample.

- The fetal sample should be analysed in duplicate and, if possible, by using two different methods. PND samples could also be split into two separate samples on arrival 
in the laboratory, and duplicates processed independently.

- PND reports should routinely be issued within 1 week of receiving the sample.

In some European centres, preimplantation genetic diagnosis (PGD) can be offered for at-risk couples as an alternative to PND. PGD should be performed according to the highest quality standards, with respect to local ethical, and legal requirements. Technical and medical procedures should be at least in agreement with the guidelines of the European Society of Human Reproduction and Embryology (ESHRE). ${ }^{57}$

\section{CF carrier screening in individuals without a family} history Attitudes regarding carrier screening in the general population differ between individual countries. In the United States, preconceptional carrier screening is recommended ${ }^{23}$ and performed using a consensus panel of CF-causing mutations, ${ }^{25}$ whereas in Europe, the situation is much more heterogeneous: ${ }^{58}$ population screening was implemented in a number of different regional or national programmes, especially as prenatal screening, ${ }^{59-61}$ while it is not recommended in other countries. Despite the absence of European consensus for recommendation of $\mathrm{CF}$ screening in couples seeking preconceptional counselling, appropriate information about the disease and its genetic aspects, as well as the possibility and the limits of testing, should be provided on request.

CF carrier testing in infertile couples (non-CBAVD couples) Recommendation of CF screening in the case of in vitro fertilization (IVF) procedures ${ }^{62}$ is not widely shared among European Genetics societies, as the risk of carrying a CF mutation is not significantly higher than that of the general population. However, this issue may be discussed with couples in a genetic counselling session before IVF.

\section{Consideration of ethnic/geographic origins}

In addition to the screen for frequent mutations, a complementary panel may be required to test population-specific mutations with a frequency above $1 \%$. Knowledge of the ethnic or geographic origins of patients and their parents and grandparents is therefore important to determine the analysis to be performed.

These studies should be considered in the following situations: (1) carrier testing, especially in partners of $\mathrm{CF}$ carriers or patients; (2) fetal bowel anomalies when no mutation of the basic panel is found but where consanguinity is documented, or in case of decreased intestinal enzyme activities in amniotic fluid. Where a parent is found to be a CF carrier, knowledge of the other parent's origin could help to target the exons to be first analysed for searching a potential second CF mutation.

Data on disease and carrier frequencies as well as on mutation frequencies in various populations are available in the latest WHO report ${ }^{63}$ and in the literature. ${ }^{6-8}$

\section{Guidelines for interpretation}

Consideration on the classification of CFTR mutations CFTR sequence variants are associated with a broad range of phenotypes, mainly due to their varied effects on protein synthesis and function.

Many clinicians and laboratories use 'mutation' and 'polymorphism' to indicate 'disease-causing' and 'neutral/ benign' variants, respectively, a practice that is incorrect and should be avoided. The terms mutation and 'sequence variant or alteration' are formally synonymous and do not denote any functional consequence or disease association, whereas polymorphism formally designates a variant with an allelic frequency over $1 \%$ in the general population irrespective of any clinical significance. It is essential for laboratories to make clear whether a detected variant is predicted to cause $\mathrm{CF}$, to have a severe or moderate effect, to be associated with CFTR-RD, or to be phenotypically neutral.

The classification of CFTR gene mutations according to their functional effects on CFTR protein production and function, ${ }^{64,65}$ based on functional studies, has been widely used in the scientific literature. However, only a limited number of mutations have been studied and many CFTR mutations have different functional consequences and cannot be assigned to one particular class. In other respects, it should be noted that the categorization of CFTR mutations is not predictive of individual outcomes. CFTR genotype/phenotype correlations may be used at a population level to determine associations, but should not be used to indicate prognosis in individual patients.

A classification of CFTR gene mutations, based on their potential for causing disease and their implication for genetic counselling, that is, whether they should be considered for PND and cascade carrier testing, may be used instead. A number of criteria are taken into account to determine which effect a sequence variation may have (Lists below). 1,66,67 Mutations may be clustered in four groups (Table 4): (A) mutations that cause CF disease; (B) mutations that result in a CFTR-RD; (C) mutations with no clinical consequences; (D) mutations of unproven or uncertain clinical relevance.

Only mutations that cause CF should be considered for carrier testing and PND provided both couple members are carriers. Some CF mutations may be associated with a wide phenotypic spectrum and discussion should take into account these generally milder phenotypes. As a precaution, mutations of unproven or uncertain clinical relevance may be considered as potentially 
Table 4 Classification of CFTR mutations with regard to their potential for causing disease

\begin{tabular}{|c|c|}
\hline Mutation group & Examples \\
\hline CF-causing & $\begin{array}{l}\text { F508del } \\
\text { Mainly nonsense, frameshift, splicing (invariant dinucleotide): G542X, R553X, W1282X, 2183AA }>\text { G, } \\
3659 \text { delC, } 1717-1 \mathrm{G}>\mathrm{A}, 3120+1 \mathrm{G}>\mathrm{A} \\
\text { Missense that severely affects CFTR synthesis or function: G551D, N1303K, R347P } \\
2789+5 \mathrm{G}>\mathrm{A}, 3849+10 \mathrm{kbC}>\mathrm{T}, 3272-26 \mathrm{~A}>\mathrm{G}, \mathrm{L} 206 \mathrm{~W}^{\mathrm{a}}, \mathrm{D} 1152 \mathrm{H}^{\mathrm{a}},(\mathrm{TG}) 13(\mathrm{~T}) 5^{\mathrm{a}}\end{array}$ \\
\hline $\begin{array}{l}\text { CFTR-related disorders } \\
\text { associated }\end{array}$ & $\begin{array}{l}\text { L206W }^{\mathrm{a}}, \mathrm{D} 1152 \mathrm{H}^{\mathrm{a}},(\mathrm{TG}) 13(\mathrm{~T}) 5^{\mathrm{a}} \\
\text { [R117H;(T)7], (TG)12(T)5, L997F, V562I, [R668C;G576A;D443Y], [R74W;D1270N] } \\
\text { (TG)11(T)5 } 5^{\mathrm{b}}, \mathrm{S} 1235 \mathrm{R}^{\mathrm{b}}\end{array}$ \\
\hline No clinical consequences & $\begin{array}{l}875+40 \mathrm{~A}>\mathrm{G}, \mathrm{M} 470 \mathrm{~V}(1540 \mathrm{~A}>\mathrm{G}), 1506 \mathrm{~V}(1648 \mathrm{~A}>\mathrm{G}), \mathrm{F} 508 \mathrm{C}(1655 \mathrm{~T}>\mathrm{G}), 1716 \mathrm{G}>\mathrm{A}, 2694 \mathrm{~T}>\mathrm{G} \\
4002 \mathrm{~A}>\mathrm{G}, 2752-15 \mathrm{C}>\mathrm{C} \\
(\mathrm{TG}) 11(\mathrm{~T}) 5^{\mathrm{b}}, \mathrm{S} 1235 \mathrm{R}^{\mathrm{b}}\end{array}$ \\
\hline $\begin{array}{l}\text { Unproven or uncertain } \\
\text { clinical relevance }\end{array}$ & $\begin{array}{l}\text { Mainly missense mutations } \\
\text { G622D, R170H, V938G, I125T } \\
\text { Putative splice mutations: } 406-6 \mathrm{~T}>\mathrm{C}, 2752-26 \mathrm{~A}>\mathrm{G}, 3601-17 \mathrm{~T}>\mathrm{C}\end{array}$ \\
\hline
\end{tabular}

Only a fraction of mutations and patients have been characterized in detail and, with the exception of frequent mutations, only small numbers of patients have been available for the study of most mutations. Data shown here have to be interpreted with caution.

${ }^{a}$ Mutations that are associated with a wide phenotypic spectrum and which may belong either to group A or to group B.

${ }^{\mathrm{b}}$ Mutations that may belong either to group B or to group C.

CF causing. However, a thorough examination of the CFTR gene should be performed to search for complex alleles whenever variants of unpredictable effect are identified.

Because of the interplay of the CFTR genotype and other genetic or environmental factors, there may be overlapping of groups.

Criteria for mutations predicted to cause CF:

(1) Criteria of high degree of certainty:

- Cause a change in the amino-acid sequence that severely affects CFTR synthesis and/or function

- Introduce a premature termination signal (insertion, deletion, or nonsense)

- Alter the invariant nucleotides GT/AG of intron splice sites

- Delete one or more exons

(2) Criteria of a lower degree of certainty:

- Cause a novel amino-acid sequence that does not occur in the normal CFTR gene from at least 100 carriers of CF mutations from the patient's ethnic group

- Change a highly evolutionarily conserved amino-acid residue

- Create a novel/cryptic splice site

- Similar sequence variations are found in other genes of the ATP-Binding Cassette family

Indirect evidence that a CFTR mutation does not cause CF:

- The other allele is carrying a well-known CF-causing mutation in a clearly asymptomatic individual
- A silent exonic mutation, without a priori splicing modification

- An intronic mutation outside the known consensus sites and which does not create a predicted splicing site

- Frequency in the general population is higher than in the CF population. ${ }^{68}$

Novel sequence changes may be subjected to the analysis by computer algorithms to assist in determining their potential pathogenicity. Such programmes include SIFT, ${ }^{69}$ Polyphen, ${ }^{70}$ and Splice site prediction. ${ }^{71}$

Comments on particular sequence variations $\mathbf{T}(5)$ The (T)5 splicing variant of the intron 8 acceptor splice site is not considered a CF-causing mutation but CFTR-RD-associated. It should not, therefore, be tested in the context of carrier testing in relatives, partners of carriers and of patients, and in the cases of fetal bowel anomalies.

There are three common alleles at the polypyrimidine tract of the intron 8 acceptor splice site: (T)5, (T)7, and (T) 9 (5, 7, and 9 thymidines, respectively). The lower the number of thymidines, the lower the efficiency of exon 9 splicing. The extent of splicing is further affected by the number of adjacent (TG) repeats, thereby modulating the disease penetrance of the (T) 5 variant: ${ }^{72,73}$ the higher the number of (TG) repeats, the lower the efficiency of splicing. A (T)5 variant can either be associated with (TG)11, (TG)12, (TG)13, and rarely (TG) 15 repeats. ${ }^{74}$

When (T)5 is found in diagnostic testing, for example, for CBAVD or atypical presentation, determination of 
the adjacent (TG) length should be performed. Patients carrying (TG)12(T)5 or, more importantly, (TG)13(T)5, in trans with a CF-causing mutation, might develop other symptoms suggestive of a mild form of $\mathrm{CF}$, and thus need clinical evaluation and long-term followup (Figure 3).

When (T) 5 is found in a patient with typical CF or in the context of neonatal screening, whatever the (TG) length, other mutations in cis (forming complex alleles) should be sought.

I148T Was initially described as a frequent CF-causing mutation. However, recent data have provided evidence that it is not CF-causing in itself. ${ }^{75-77}$ In CF patients, other mutations in cis should be sought, in particular 3199del6 (located in exon 17a). I148T should not be routinely screened for and is currently being removed from the panels of commercial assays. ${ }^{25}$

R117H Can be found in cis with IVS8 (T)5 or (T)7. [R117H;(T)5] is considered a mild CF-causing complex allele, whereas [R117H;(T)7] is considered more as a CFTR-RD mutation. In neonatal screening programmes, the high frequency of $\mathrm{R} 117 \mathrm{H}$ in newborns with elevated immunoreactive trypsinaemia $^{78}$ has raised the question of its penetrance and its clinical significance for genetic counselling. So far, children who are compound heterozygous for [R117H;(T)7] and a severe CF-causing mutation have shown no clinical signs of $\mathrm{CF}^{78}$ Given these observations, identification of $\mathrm{R} 117 \mathrm{H}$ in trans with F508del in neonates should be completed by IVS 8 poly(T) testing. If $\mathrm{R} 117 \mathrm{H}$ is in cis with (T)7, genetic counselling should be reassuring.

\section{Guidance for risk calculation}

Because of the incomplete sensitivity of molecular tests, in case of negative results, comments on residual CF carrier risk and reproductive risk for couples should be provided where appropriate. These posterior risks, based on a test result, take into account the sensitivity of the test and the prior risk of CF or of CF carriers. Such complex risk calculations should ideally be made using Bayesian analysis. Risks may be calculated by using computer programmes like the traditional and freely available LINKAGE suite from Jurg Ott (http://linkage.rockefeller.edu/). Alternatively, the calculation can be made 'by hand':

$\mathrm{P}(\mathrm{C} \mid$ no mut $)=\frac{\mathrm{P}(\mathrm{C}) \times \mathrm{P}(\text { no mut } \mid \mathrm{C})}{\mathrm{P}(\mathrm{C}) \times \mathrm{P}(\text { no mut } \mid \mathrm{C})+\mathrm{P}(\text { no } \mathrm{C}) \times \mathrm{P}(\text { no mut } \mid \text { no } \mathrm{C})}$

$\mathrm{P}$ : probability; C: carrier; no mut: no mutation; $\mathrm{P}(\mathrm{C} \mid$ no mut): probability that the individual is a carrier, provided that he tested negative for the investigated mutations.

Many scenarios for CF risk calculations have recently been assessed by Ogino et al; ${ }^{79-81}$ other examples were presented in the previous version of these recommendations. ${ }^{20}$

In many situations where prior probabilities are in clearly different ranges (for instance $1 / 25$ of being a carrier and $24 / 25$ of being non-carrier), risk calculations can be performed by using simplified formulae, ${ }^{20}$ which consist in assimilating the overall probability of having a negative result (denominator of the above formula) to 1 (100\%). The simplified formulae are easy to use and the error, compared with the mathematically more correct ones, is often very small. This error might be even smaller than the error of the input parameter for CF prevalence (Table 5, Example 1).

Table 5 Risk calculation using Bayesian and simplified formulae

\begin{tabular}{|c|c|c|c|c|c|c|}
\hline & \multicolumn{4}{|c|}{$\begin{array}{c}\text { Example } 1^{\mathrm{a}} \\
74 \%\end{array}$} & \multicolumn{2}{|c|}{ Example $2^{\mathrm{b}}$} \\
\hline $\begin{array}{l}\text { Mutation detection rate } \\
\text { Family history }\end{array}$ & & & \\
\hline CF prevalence & \multicolumn{2}{|c|}{$1 / 3300$} & \multicolumn{2}{|c|}{$1 / 2500$} & \multicolumn{2}{|c|}{ Any prevalence } \\
\hline Hypothesis & Carrier & Non-carrier & Carrier & Non-carrier & Carrier & Non-carrier \\
\hline $\begin{array}{l}\text { Prior probability } \\
\text { Conditional probability }^{\mathrm{d}} \\
\text { Joint probability }^{\mathrm{e}} \\
\text { Posterior probability }^{\mathrm{f}} \\
\text { Simplified posterior probability }^{\mathrm{g}}\end{array}$ & $\begin{array}{c}1 / 29 \\
26 / 100 \\
26 / 2900 \\
1 / 109 \\
1 / 111\end{array}$ & $\begin{array}{c}28 / 29 \\
1 \\
28 / 29 \\
108 / 109 \\
110 / 111\end{array}$ & $\begin{array}{c}1 / 25 \\
26 / 100 \\
26 / 2500 \\
1 / 93 \\
1 / 96\end{array}$ & $\begin{array}{c}24 / 25 \\
1 \\
24 / 25 \\
92 / 93 \\
95 / 96\end{array}$ & $\begin{array}{c}1 / 2 \\
10 / 100 \\
10 / 200 \\
1 / 11 \\
1 / 20\end{array}$ & $\begin{array}{c}1 / 2 \\
1 \\
1 / 2 \\
10 / 11 \\
19 / 20\end{array}$ \\
\hline $\begin{array}{l}{ }^{\mathrm{a}} \text { Exposes the posterior carrier risk cal } \\
\text { using two different CF prevalence } \mathrm{v} \\
\mathrm{b}^{\mathrm{b}} \text { Exposes the posterior carrier risk ca } \\
\text { (shaded area). A brother of the test } \\
{ }^{\text {c} C a r r i e r ~ f r e q u e n c y ~ a c c o r d i n g ~ t o ~ t h e ~} \\
{ }^{\mathrm{d}} \text { Probability that a carrier tests 'neg } \\
\text { eProduct of prior and conditional p } \\
\text { f Joint probability for that hypothesis } \\
\text { given that he tested 'negative'. }\end{array}$ & $\begin{array}{l}\text { under the } \\
\text { haded are } \\
\text { under th } \\
\text { idual has } \\
\text { F prevale } \\
r \text { the dete } \\
\text { by the su }\end{array}$ & $\begin{array}{l}\text { ion that } C F T \\
\text { tion that } C F \\
\text { dren with } C F \\
\text { ie population } \\
\text { iutations. } \\
\text { int probabili }\end{array}$ & $\begin{array}{l}\text { g was neg } \\
\text { gen was ne } \\
\text { genotype } \\
\text { gesian anal }\end{array}$ & $\begin{array}{l}\text { a healthy ind } \\
\text { a healthy in } \\
\text { brother and } \\
\text { his is the prob }\end{array}$ & $\begin{array}{l}\text { with a f } \\
\text { ildren are }\end{array}$ & $\begin{array}{l}\text { istory of } \mathrm{CF} \text {, } \\
\text { istory of } \mathrm{CF} \\
\mathrm{vn.} \\
\text { is a carrier, }\end{array}$ \\
\hline
\end{tabular}


In other cases where prior probabilities of both hypotheses are of similar magnitude, it is necessary to use Bayesian analysis instead of simplified formulae, since the mathematically correct result differs substantially and may lead to erroneous conclusions. In Example 2 in Table 5, both hypotheses of being and not being a carrier have a prior probability of approximately $\frac{1}{2}$; the result obtained by the simplified calculations is almost in the range of the general carrier frequency $(1 / 20$ versus $1 / 25)$, whereas the mathematically correct result $(\approx 1 / 11)$ yields a much higher carrier probability. Carrier testing for the partner should clearly be offered in the case of an individual with a $1 / 11$ carrier probability, but this is less evident if the carrier probability is approximately the same as in the general population. The simplified posterior probability in this example would thus be, misleadingly, $\frac{1}{2} \times 10 / 100=1 / 20$.

\section{Reporting the results}

Genetic test results should be communicated to the referring physician or genetic professional and to any physician designated by the patient. Reports of the test results should be issued in a standardized form, clearly intelligible to the non-specialist. Items that should be included in a standard molecular analysis laboratory report are listed in the list below. Reports should, as far as possible, answer the question asked by the clinician. It is suggested that important remarks are highlighted in bold, for example, the patient's genotype and clinical implications, whereas technical details may be written in smaller characters or presented in footnotes. To avoid confusion, it is suggested that sequence variations with no clinical consequences (for example, 1540A $>\mathrm{G}(\mathrm{M} 470 \mathrm{~V})$ ) are not reported. If it is not clear whether the identified mutation is neutral or putatively disease causing, the interpretation should include a statement such as: 'mutation of unproven or uncertain clinical relevance'. It must be recognized that an individual's negative result does not exclude the presence of undetected CFTR mutations. Along with the report, a pedigree with the genotype information may be included, if applicable (eg, linkage study).

In general, the laboratory should not directly report results to the patient and should ensure that the clinician reporting to the patient has a full understanding of the results and their underlying clinical meaning.

No information regarding the mutation analysis results should be communicated to the third parties without the consent of the individual tested or his/her representative.

Content of a standard report for CFTR gene molecular analysis

- Laboratory that issues the report: name and address

- Title, that is, 'CFTR molecular analysis'

- Date of report

- Referring doctor/clinician: name and affiliation
- Patient/individual:

- Name and first name

- Date of birth

- Gender

- Geographic or ethnic origin (patient, parents, and grandparents, if possible)

- Reason for testing: restated in full and not abbreviated

- Sample:

- Collection date, if available

- Arrival date

- Nature of the sample (eg, blood, chorionic villus biopsy)

- Laboratory identification number of sample and family (if it has been assigned)

- Method:

- Name of the method, version of the commercial assay whenever used

- List of mutations and/or exons analysed

- Detection rate/sensitivity in the respective patient's population

- Results: the CFTR mutations identified and genotype established for the individual, or negative results

- Interpretation of the data that should relate to:

- The reason for testing (eg, prenatal diagnosis, carrier testing)

- The clinical significance of the detected mutations (eg, CF-causing mutation, mutation with uncertain clinical relevance)

- The residual risk whenever appropriate (eg, CF carrier risk)

- Possible recommendations for the genetic counselling and future testing (eg, clinical or genetic testing of family members, PND)

- Signature of the laboratory director or other authorized individual and his/her name

- Total number of pages

\section{Nomenclature for designation of mutations}

A systematic common nomenclature is essential for the description of mutations in reports, publications, and mutation databases. It helps clinical geneticists to provide accurate information for diagnosis and genetic counselling, and researchers to determine whether a specific mutation has been described as well as to identify patients with the same mutations.

Laboratories must take care to report mutations in a way that is both understandable and unambiguous. Most laboratories currently use the traditional nomenclature, according to the CF Mutation Database. ${ }^{8}$ Human Genome Variation Society (HGVS) nomenclature ${ }^{82}$ may be more precise in some situations but can also lead to confusion. For example, HGVS defines the ' $\mathrm{A}$ ' of the translation initiation codon as +1 (traditionally +133 ) 
leading to the common mutation 1717-1 G $>$ A becoming c. $1585-1 \mathrm{G}>$ A.

At present, the use of the traditional nomenclature is recommended. The symbol $\Delta$ should be avoided; F508del and I507del are preferred. If HGVS nomenclature is used, we recommend that the traditional names also be given, to improve the understanding by the referring clinician.

The CF consortium intends to list both the traditional and HGVS nomenclature in parallel in its CF Mutation Database (J Zielenski, personal communication 2007).

\section{Conclusions}

The recommendations described here are an attempt to improve the quality of CFTR mutation testing and promote this as a model for improvement of the overall quality of genetic testing. Harmonization of procedures and the creation of collaborative networks of laboratories should assure a high level of quality of genetic testing to the benefit of patients, families, and the general population. Education of the laboratory staff, clinicians, and all individuals concerned with all aspects of CF and related CFTR pathology should be encouraged. Despite possible unequal access to health care between countries or regions, exchanges and discussions at regional, national, or supranational levels, based on these guidelines, should further help laboratories to obtain facilities and equipment from their authorities. Since the field is steadily evolving in terms of knowledge of the molecular pathology and of genotype-phenotype correlations and due to continuous improvement of diagnostic tools and procedures, these guidelines need to be updated on a regular basis.

\section{Acknowledgements}

This study was supported and performed within the framework of the EU project EuroGentest (FP6-512148) and the European Cystic Fibrosis Network.

\section{References}

1 Rosenstein BJ, Cutting GR: The diagnosis of cystic fibrosis: a consensus statement. J Pediatr 1998; 132: 589-595.

2 Orenstein DM, Winnie GB, Altman H: Cystic fibrosis: a 2002 update. J Pediatr 2002; 140: 156-164.

3 World Health Organisation: Classification of cystic fibrosis and related disorders. Report of a joint working group of $\mathrm{WHO} /$ ICF(M)A/ECFS/ECFTN. J Cyst Fibros 2002; 1: 5-8.

4 Boyle MP: Nonclassic cystic fibrosis and CFTR-related diseases. Curr Opin Pulm Med 2003; 9: 498-503.

5 Goss $\mathrm{CH}$, Rosenfeld M: Update on cystic fibrosis epidemiology. Curr Opin Pulm Med 2004; 10: 510-514.

6 Estivill X, Bancells C, Ramos C, Consortium: TBCMA: geographic distribution and regional origin of 272 cystic fibrosis mutations in European populations. Hum Mutat 1997; 10: 135-154.
7 Bobadilla JL, Macek Jr M, Fine JP, Farrell PM: Cystic Fibrosis: a worldwide analysis of CFTR mutations - correlation with incidence data and application to screening. Hum Mutat 2002; 19: $575-606$.

8 Cystic Fibrosis Mutation Database: www.genet.sickkids.on.ca/cftr/.

9 Chillon M, Casals T, Mercier B et al: Mutations in the cystic fibrosis gene in patients with congenital absence of the vas deferens. N Engl J Med 1995; 332: 1475-1480.

10 Dörk T, Dworniczak B, Aulehla-Scholz C et al: Distinct spectrum of CFTR gene mutations in congenital absence of vas deferens. Hum Genet 1997; 100: 365-377.

11 Casals T, Bassas L, Egozcue S et al: Heterogeneity for mutations in the CFTR gene and clinical correlations in patients with congenital absence of the vas deferens. Hum Reprod 2000; 15: $1476-1483$.

12 Claustres M, Guittard C, Bozon D et al: Spectrum of CFTR mutations in cystic fibrosis and in congenital absence of the vas deferens in France. Hum Mutat 2000; 16: 143-156.

13 Ratbi I, Legendre M, Niel F et al: Detection of cystic fibrosis transmembrane conductance regulator (CFTR) gene rearrangements enriches the mutation spectrum in congenital bilateral absence of the vas deferens and impacts on genetic counselling. Hum Reprod 2007; 22: 1285-1291.

14 Girodon E, Cazeneuve C, Lebargy F et al: CFTR gene mutations in adults with disseminated bronchiectasis. Eur J Hum Genet 1997; 5: 149-155.

15 Pignatti PF, Bombieri C, Marigo C, Benetazzo M, Luisetti M: Increased incidence of cystic fibrosis gene mutations in adults with disseminated bronchiectasis. Hum Mol Genet 1995; 4: $635-639$.

16 Cohn JA, Friedman KJ, Noone PG, Knowles MR, Silverman LM, Jowel PS: Relation between mutations of the cystic fibrosis gene and idiopathic pancreatitis. $N$ Engl J Med 1998; 339: 653-658.

17 Sharer N, Schwarz M, Malone G et al: Mutations of the cystic fibrosis gene in patients with chronic pancreatitis. $N$ Engl J Med 1998; 339: 645-652.

18 Coste A, Girodon E, Louis S et al: Atypical sinusitis in adults must lead to looking for cystic fibrosis and primary ciliary dyskinesia. Laryngoscope 2004; 114: 839-843.

19 Wang X, Moylan B, Leopold DA et al: Mutation in the gene responsible for cystic fibrosis and predisposition to chronic rhinosinusitis in the general population. JAMA 2000; 284: $1814-1819$

20 Dequeker E, Cuppens H, Dodge J et al: Recommendations for quality improvement in genetic testing for cystic fibrosis. Eur I Hum Genet 2000; 8 (Supplement 2): S1-S24.

21 OECD guidelines for quality assurance in genetic testing www.oecd.org/document/24.

22 Castellani C, Cuppens H, Macek Jr M: et al: Consensus on the use and interpretation of cystic fibrosis mutation analysis in clinical practice. J Cyst Fibros 2008; 7: 179-196.

23 Grody WW, Cutting GR, Klinger KW et al: Laboratory standards and guidelines for population-based cystic fibrosis carrier screening. Genet Med 2001; 3: 149-154.

24 Richards CS, Bradley LA, Amos J et al: Standards and guidelines for CFTR mutation testing. Genet Med 2002; 4: 379-391.

25 Watson MS, Cutting GR, Desnick RJ et al: Cystic fibrosis population carrier screening: 2004 revision of American college of medical genetics mutation panel. Genet Med 2004; 6: 387-391.

26 Audrézet MP, Chen JM, Raguenes O et al: Genomic rearrangements in the CFTR gene: extensive allelic heterogeneity and diverse mutational mechanisms. Hum Mutat 2004; 23: 343-357.

27 Hantash FM, Redman JB, Starn $\mathrm{K}$ et al: Novel and recurrent rearrangements in the CFTR gene: clinical and laboratory implications for cystic fibrosis screening. Hum Genet 2006; 17: $1-11$.

28 Niel F, Martin J, Dastot-Le Moal F et al: Rapid detection of CFTR gene rearrangements impacts on genetic counselling in cystic fibrosis. J Med Genet 2004; 41: e118. 
29 Bombieri C, Bonizzato A, Castellani C, Assael BM, Pignatti PF: Frequency of large CFTR gene rearrangements in Italian CF patients. Eur J Hum Genet 2005; 13: 687-689.

30 Ferec C, Casals T, Chuzhanova $\mathrm{N}$ et al: Gross genomic rearrangements involving deletions in the CFTR gene: characterization of six new events from a large cohort of hitherto unidentified cystic fibrosis chromosomes and meta-analysis of the underlying mechanisms. Eur J Hum Genet 2006; 14: 567-576.

31 Montgomery J, Wittwer C, Kent J, Zhou L: Scanning the cystic fibrosis transmembrane conductance regulator gene using high-resolution DNA melting analysis. Clin Chem 2007; 53: $1891-1898$.

32 Mekus F, Ballmann M, Bronsveld I et al: Cystic-fibrosis-like disease unrelated to the cystic fibrosis transmembrane conductance regulator. Hum Genet 1998; 102: 582-586.

33 Groman JD, Meyer ME, Wilmott RW, Zeitlin PL, Cutting GR: Variant cystic fibrosis phenotypes in the absence of CFTR mutations. N Engl Jl Med 2002; 347: 401-407.

34 Sheridan MB, Fong P, Groman JD et al: Mutations in the betasubunit of the epithelial $\mathrm{Na}+$ channel in patients with a cystic fibrosis-like syndrome. Hum Mol Genet 2005; 14: 3493-3498.

35 Gasparini P, Dognini M, Bonizzato A, Pignatti PF, Morral N, Estivill X: A tetranucleotide repeat polymorphism in the CFTR gene. Hum Genet 1991; 86: 625.

36 Morral N, Nunez V, Casals T, Estivill X: CA/GT microsatellite alleles within the cystic fibrosis transmembrane conductance regulator (CFTR) gene are not generated by unequal crossingover. Genomics 1991; 10: 692-698.

37 Zielenski J, Markiewicz D, Rininsland F, Rommens J, Tsui L-C: A cluster of highly polymorphic dinucleotide repeats in intron $17 \mathrm{~b}$ of the cystic fibrosis transmembrane conductance regulator (CFTR) gene. Am J Hum Genet 1991; 49: 1256-1262.

38 Morral N, Estivill X: Multiplex PCR amplification of three microsatellites within the CFTR gene. Genomics 1992; 13: $1362-1364$.

39 Moulin DS, Smith AN, Harris A: A CA repeat in the first intron of the CFTR gene. Hum Hered 1997; 47: 295-297.

40 Clarke A: The genetic testing of children. Working Party of the Clinical Genetics Society (UK). J Med Genet 1994; 31: $785-797$.

41 De Boeck K, Wilschanski M, Castellani C. et al: Cystic fibrosis: terminology and diagnostic algorithms. Thorax 2006; 61: $627-635$

42 Cremonesi L, Cainarca S, Rossi A, Padoan R, Ferrari M: Detection of a de novo $\mathrm{R} 1066 \mathrm{H}$ mutation in an Italian patient affected by cystic fibrosis. Hum Genet 1996; 98: 119-121.

43 White $\mathrm{MB}$, Leppert $\mathrm{M}$, Nielsen $\mathrm{D}$ et al: $\mathrm{A}$ de novo cystic fibrosis mutation: CGA (Arg) to TGA (stop) at codon 851 of the CFTR gene. Genomics 1991; 11: 778-779.

44 Beaudet AL, Perciaccante RG, Cutting GR: Homozygous nonsense mutation causing cystic fibrosis with uniparental disomy. Am J Hum Genet 1991; 48: 1213.

45 Hehr U, Dörr S, Hagemann M, Hansmann I, Preiss U, Brömme S: Silver-Russell syndrome and cystic fibrosis associated with maternal uniparental disomy 7. Am J Med Genet 2000; 91: 237-239.

46 Le Caignec C, Isidor B, de Pontbriand U et al: Third case of paternal isodisomy for chromosome 7 with cystic fibrosis: a new patient presenting with normal growth. Am J Hum Genet A 2007; 143: 2696-2699.

47 Voss R, Ben-Simon E, Avital A et al: Isodisomy of chromosome 7 in a patient with cystic fibrosis: could uniparental disomy be common in humans? Am J Hum Genet 1989; 45: 373-380.

48 Jarvi K, Zielenski J, Wilschanski $\mathrm{M}$ et al: Cystic fibrosis transmembrane conductance regulator and obstructive azoospermia. Lancet 1995; 345: 1578.

49 Mak V, Zielenski J, Tsui LC et al: Proportion of cystic fibrosis gene mutations not detected by routine testing in men with obstructive azoospermia. JAMA 1999; 281: 2217-2224.
50 Zielenski J: Genotype and phenotype in cystic fibrosis. Respiration 2000; 67: 117-133.

51 Simon-Bouy B, Satre V, Ferec C et al: Hyperechogenic fetal bowel: a large French collaborative study of 682 cases. Am J Med Genet A 2003; 121: 209-213.

52 Corteville JE, Gray DL, Langer JC: Bowel abnormalities in the fetus-correlation of prenatal ultrasonographic findings with outcome. Am J Obstet Gynecol 1996; 175: 724-729.

53 Muller F, Dommergues M, Simon-Bouy B et al: Cystic fibrosis screening: a fetus with hyperechogenic bowel may be the index case. J Med Genet 1998; 35: 657-660.

54 Muller F, Simon-Bouy B, Girodon E et al: Predicting the risk of cystic fibrosis with abnormal ultrasoud signs of fetal bowel. Results of a french molecular collaborative study based on 641 prospective cases. Am J Med Genet 2002; 110: 109-115.

55 Slotnick RN, Abuhamad AZ: Prognostic implications of fetal echogenic bowel. Lancet 1996; 347: 85-87.

56 Welsh MJ, Tsui LC, Boat TF, Beaudet AL: Cystic fibrosis; in Scriver $\mathrm{CR}$, Beaudet AL, Sly WS, Valle D (eds):: The Metabolic and Molecular Bases of Inherited Disease. New York: McGraw-Hill Health Professions, 1995, 7th edn, vol III, pp 3799-3876.

57 Thornhill AR, deDie-Smulders CE, Geraedts JP et al: ESHRE PGD Consortium 'Best practice guidelines for clinical preimplantation genetic diagnosis (PGD) and preimplantation genetic screening (PGS). Hum Reprod 2005; 20: 35-48.

58 Godard B, ten Kate L, Evers-Kiebooms G, Aymé S: Population genetic screening programmes: principles, techniques, practices, and policies. Eur J Hum Genet 2003; 11 (Suppl 2): S49-S87.

59 Brandt NJ, Schwartz M, Skovby F: Screening for carriers of cystic fibrosis. Result of a pilot study among pregnant women. Ugeskr Laeger 1994; 156: 3751-3754, 3757.

60 Shrimpton AE, McIntosh I, Brock DJ: The incidence of different cystic fibrosis mutations in the Scottish population: effects on prenatal diagnosis and genetic counselling. J Med Genet 1991; 28: 317-321.

61 Witt DR, Schaefer C, Hallam P et al: Cystic fibrosis heterozygote screening in 5161 pregnant women. Am J Hum Genet 1996; 58: 823-835.

62 Foresta C, Ferlin A, Gianaroli L, Dallapiccola B: Guidelines for the appropriate use of genetic tests in infertile couples. Eur J Hum Genet 2002; 10: 303-312.

63 The molecular epidemiology of cystic fibrosis www.who.int/ genomics/publications/en/.

64 Kerem B, Kerem E: The molecular basis for disease variability in cystic fibrosis. Eur J Hum Genet 1996; 4: 65-73.

65 Welsh MJ, Smith AE: Molecular mechanisms of CFTR chloride channel dysfunction in cystic fibrosis. Cell 1993; 73: 1251-1254.

66 ACMG Laboratory Practice Committee Working Group: ACMG recommendations for standards for interpretation of sequence variations. Genet Med 2000; 2: 302-303.

67 Bell J, Bodmer D, Sistermans E, Ramsden SC: Practice guidelines for the interpretation and reporting of unclassified variants (UVs) in clinical molecular genetics. Guidelines ratified by the UK CMGS (11th January, 2008) and the VGKL (22nd October, 2007). http://cmgsweb.shared.hosting.zen.co.uk/BPGs/Best_practice_Guide lines.htm.

68 Bombieri C, Giorgi S, Carles S: et al: A new approach for identifying non-pathogenic mutations. An analysis of the cystic fibrosis transmembrane regulator gene in normal individuals. Hum Genet 2000; 106: 172-178.

69 SIFT: http://blocks.fhcrc.org/sift/SIFT.html

70 Polyphen: http://genetics.bwh.harvard.edu/pph/

71 Splice site prediction: www.fruitfly.org/seq_tools/splice.html.

72 Cuppens $\mathrm{H}$, Lin W, Jaspers $\mathrm{M}$ et al: Polyvariant mutant cystic fibrosis trensmembrane conductance regulator genes. J Clin Invest 1998; 101: 487-496.

73 Groman JD, Hefferon TW, Casals T et al: Variation in a repeat sequence determines whether a common variant of the cystic fibrosis transmembrane conductance regulator gene is pathogenic or benign. Am J Hum Genet 2004; 74: 176-179. 
74 Picci L, Cameran M, Scarpa M et al: TG15 T5 allele in clinically discordant monozygotic twins with cystic fibrosis. Am J Med Genet A 2007; 143: 1936-1937.

75 Rohlfs EM, Zhou Z, Sugarman EA et al: The I148T CFTR allele occurs on multiple haplotypes: a complex allele is associated with cystic fibrosis. Genet Med 2002; 4: 319-323.

76 Buller A, Olson S, Redman JB, Hantash F, Chen R, Strom CM: Frequency of the cystic fibrosis 3199del6 mutation in individuals heterozygous for I148T. Genet Med 2004; 6: 108-109.

77 Claustres M, Altieri JP, Guittard C, Templin C, Chevalier-Porst F, Des Georges M: Are p.I148T, p.R74W and p.D1270N cystic fibrosis causing mutations? BMC Med Genet 2004; 5: 19.

78 Scotet V, Audrézet MP, Roussey M et al: Immunoreactive trypsin/ DNA newborn screening for cystic fibrosis: should the R117H variant be included in CFTR mutation panels? Pediatrics 2006; 118: $1523-1529$.

79 Ogino S, Wilson RB: Bayesian analysis and risk assessment in genetic counseling and testing. J Mol Diagn 2004; 6: $1-9$.

80 Ogino S, Wilson RB, Gold B, Hawley P, Grody WW: Bayesian analysis for cystic fibrosis risks in prenatal and carrier screening. Genet Med 2004; 6: 439-449.

81 Ogino S, Wilson RB, Grody WW: Bayesian risk assessment for autosomal recessive diseases: fetal echogenic bowel with one or no detectable CFTR mutation. I Med Genet 2004; 41: e70.

82 Human Genome Variation Society: Nomenclature for the description of sequence variations http://www.hgvs.org/mutnomen/. 